\title{
TEORÍA CULTURAL Y MODERNIZACIÓN
}

José Manuel Merino E.

\begin{abstract}
"Contamos (...) con orientaciones teóricas generales que podrian ofrecer un marco básico referencial para hacer un intento interdisciplinario, destinado a sistematizar las contribuciones de la Prehistoria, la Antropologia, la Historia, la Sociología y las otras Ciencias Sociales, a fin de construir (y validar) una teoría general de la Modernización. Pero esta inmensa Tarea, que de hecho es el legado del pensamiento social de los siglos $x V \| I I y x \mid x$, queda, todavia, por hacerse".
\end{abstract}

(Germani, 1976)

\section{INTRODUCCIÓN}

El propósito del presente trabajo consiste básicamente en describir, en términos generales, los vínculos existentes entre la Teoría Cultural y los estudios de la Modernización. En particular, interesará examinar con algún detalle los campos potenciales de aplicación, de los distintos enfoques teóricos que configuran la disciplina antropológica, a la Modernización. En ese sentido, será importante establecer algunas premisas iniciales que fundamenten los desarrollos posteriores $y$ que otorguen el contexto adecuado a las ideas de este ensayo.

En primer lugar, debemos concordar en que la Modernización es un proceso de transformación social, institucional e individual a cuya producción concurren, entre otros, factores sociales, económicos, políticos, psicológicos y culturales; en segundo lugar, este proceso consensualmente es deseable, esto es, configura una situación que en ciertos marcos normales está asociado al progreso social, al mejoramiento de la calidad de vida individual y al bienestar de los actores involucrados. Este punto debe destacarse porque hace éticamente factible la posibilidad de examinar e interpretar teórica y empíricamente sus implicancias a fin de monitorizar su desarrollo y adecuar las estrategias teóricas que en algún modo puedan esclarecerla. Por último, entre las estrategias teóricas de mayor relevancia en el fenómeno de la modernización, se deben ubicar los estudios antropológicos; perspectiva disciplinaria que ha generado un conjunto relativamente amplio de conocimiento - de diferencial alcance explicativo-en varias dimensiones culturales concurrentes al proceso de transformación que aquí nos ocupa. 
ACERCA DE LA TEORIA CULTURAL Y SU ROL

EN LOS ESTUDIOS DE MODERNIZACIÓN

La Teoría Cultural constituye el conjunto de conocimiento científico acerca de las sociedades humanas, generados por las distintas disciplinas antropológicas. En rigor, en la historia de la Antropología, como en todas las ramas del saber científico $y$, en especial, en las Ciencias Sociales, se pueden detectar una gran cantidad de enfoques y métodos en la aprehensión de la materia-objeto, que han significado una gran dispersión y heterogeneidad de los hallazgos, procedimientos y técnicas. lo que hace dificil un tratamiento profundo y exhaustivo de las formas en que pueden vincularse sus múltiples conocimientos con el proceso de Modernización.

A pesar de esta ausencia de paradigmas teóricos codificados es posible abs. traer algunos rasgos centrales del saber antropológico y proyectar sus implicancias en el estudio de las transformaciones sociales, institucionales e individuales que incluye el proceso de Modernización. Este procedimiento necesariamente involucra seleccionar una pequeña fracción de un gran universo - caracterizado por su atomización y heterogeneidad significativa - lo que conlleva el riesgo evidente de elegir la opción menos propicia o, al menos, ceder terreno al sesgo personal, situación casi inevitable cuando se analiza nuestra propia disciplina y tanto más difícil cuando reflexionamos sobre una porción del saber que nos es ajena profesionalmente.

Desde un punto de vista epistemológico, el enfoque holístico, totalizante e integrador de la Antropología la ha caracterizado marcadamente sobre las otras disciplinas del comportamiento humano. En efecto, desde sus orígenes el estudio antropológico ha considerado como un hecho clave en el esclarecimiento cognitivo de las sociedades y culturales, la interrelación de las dimensiones económicas, políticas, sociales, culturales e ideológicas. Esta consideración, con los defectos técnicos que se le han reprochado sistemáticamente, encierra la virtud de entender los fenómenos humanos en su contexto real, multicausal e interdependiente, generando visiones holísticas que muchas veces tienen incalculable valor desde el punto de vista de los nexos o trayectorias de causalidad de los fenómenos, así, este enfoque antropológico es un valioso elemento potencialmente aplicable a los estudios de Modernización, los que, casi sin excepciones, han sido fragmentarios, sectoriales y encerrados en estrechos marcos unidisciplinarios.

En términos sustantivos, uno de los grandes aportes de la Antropología al estudio del comportamiento humano consiste precisamente en la Teoría Cultural, esto es, en las regularidades observadas en el plano de la cultura que surgen de las similitudes, variaciones $y$ heterogeneidades de los grupos humanos y sociedades, pasadas y presentes; estas regularidades conforman un fértil campo potencial de referencia para el análisis de la Modernización, en todas sus dimensiones.

En efecto, la Teoría Cultural ha codificado la investigación realizada en términos del significado que ejercen en la configuración de la vida individual y social, rasgos 
como la estructura de valores, las normas, las creencias, las actitudes, las percepciones e imágenes, las pautas y patrones, las costumbres, los hábitos, etc. Dimensiones todas que caracterizan diferentes manifestaciones de la dinámica subjetiva y que ejercen una decidida - aunque poco develada - influencia en el comportamiento individual y social de los miembros de una cultura.

En este plano, la Psicología Social y, en menor medida, la Sociología han desarrollado mediciones bastante sistemáticas de las actitudes, valores y percepciones y, en especial, del rol de estos elementos subjetivos en el comportamiento de las personas en situaciones de cambio. Sin embargo, en relación a la estructura normativa, los hábitos y costumbres, las pautas y patrones culturales, no se pueden concluir del mismo modo. Estas dimensiones, pertenecientes al dominio de la Teoría Cultural y, por tanto, parte de la materia-objeto de la Antropología, no ha recibido un adecuado manejo empírico que haya posibilitado su medición y por consiguiente su aplicación en estudios de Modernización.

Obviamente, la importancia de estos componentes culturales en el comportamiento de los individuos y sociedades, enfrentados a circunstancias de transformación, está realmente fuera de discusión. Lo que debe ser enfatizado es el descuido relativo de la investigación antropológica en la determinación de los procedimientos técnicos y operacionales que permitan su adecuada vinculación con los hechos de la realidad. En verdad, gran parte de las tareas de conexión de las pautas y patrones culturales con las realidades en estudio ha provenido de disciplinas emparentadas con la Antropología: la Sociología y la Psicología Social.

Sin embargo, la potencialidad de estos rasgos culturales en las situaciones de Modernización, son evidentes. Foster, en uno de sus trabajos más destacados, explica con gran claridad las formas concretas que adoptan estos rasgos en las situaciones sociales: en gran medida, son coadyuvantes del proceso de transformación y desarrollo, cuando son manejados con habilidad, o son decididos obstáculos a la transformación, con un poder de decisión bastante apreciable, cuando no son considerados por los agentes de cambio. Es importante establecer que estas pautas, patrones y estructura normativa, la mayor parte de las veces, no sólo se oponen al cambio sino que frecuentemente son incompatibles con éste. En verdad, representan todo el poder de la situación tradicional y operan como agentes inconscientes de mantenimiento de estas condiciones. En esta perspectiva, su consideración entre los variables condicionantes del proceso de transformación, es un elemento clave para el éxito de la estrategia de Modernización adoptada.

Por otra parte, la Modernización como proceso de transformación altera profundamente la estructura de estos rasgos culturales presentes en la sociedad en expansión. Este hecho otorga mayor valor a la consideración de los patrones culturales en las situaciones de transición y cambio. Ha sido demostrado por Kluckhohn que existen relaciones bien determinadas entre, por ejemplo, el tamaño de los grupos sociales y las características de sus sistemas de valores. Esto quiere 
decir, por tanto, que uno de los procesos más utilizados por los especialistas como indicador de Modernización, a saber, la urbanización, produce profundas alteraciones en la estructura valórica de la sociedad.

Este fenómeno es algo que ha sido relativamente poco estudiado: los efectos culturales de la Modernización. Tiene, sin embargo, la más grande importancia. No es casualidad que las sociedades más modernas hayan generado en su interior catastróficas crisis de valores, elevadas tasas de anomia, hayan extendido al máximo el stress y se consuman en etapas de gran decadencia moral e institucional. Son efectos culturales incontrolados de un proceso de transformación. Son los llamados "efectos indeseables" de las políticas de expansión, que al no considerar la influencia en las estructuras de sus rasgos culturales, arrasa con ellas en un lapso tan corto que el conflicto de normas, valores, pautas y patrones, amenaza a veces la vida misma del grupo.

Al retomar las ideas globales que hemos manejado en este ensayo, debemos ahora especificar con mayores detalles las formas concretas, mediante las cuales la Modernización podría beneficiarse con una aplicación potencial de estos elementos de la Teoría Cultural. Permítasenos en este sentido establecer dos grandes ideas directrices que sintetizan lo que, a nuestro juicio, sería una vinculación eficiente entre la Teoría Cultural y la Modernización.

La tradición de los estudios de Modernización nos demuestra que ha habido, en estos años, un fructífero énfasis en la descripción de los tipos ideales de la estructura normativa que caracteriza a la "mentalidad tradicional" y a la "mentalidad moderna", en el entendido que al comparar ambos conjuntos de rasgos surgirán de modo inequívoco los factores que controlados y/o manipulados posibiliten la monitorización adecuada que haga factible una modernización de estructuras, organizaciones y mentalidades, eficaz, rápida e isomórfica respecto de los adelantos materiales $y$ técnicos.

En este aspecto, los trabajos de Weber acerca de la racionalidad y la secularización, los de Parsons acerca de las variables-pautadas, los de McClelland acerca de la necesidad de logro, de Rogers acerca de la capacidad de innovar, de Lerner acerca de la empatía, de Riesman referidos a la heterodirección, etc., son buenos ejemplos de cómo las perspectivas sociológicas y psicológicas se han instrumentalizado para producir procedimientos de medida que han permitido un descenso empírico de la teoría, lo que ha hecho factible crear un cuerpo de conocimientos de alcance medio que ha presentado un decidido impulso a los estudios de los procesos de Modernización.

Sin embargo, en la Teoría Cultural o, más precisamente, en ciertos segmentos de ella como en la estructura de valores, de creencias, de costumbres, de hábitos, etc., no ha existido este proceso operativo que permita la manipulación de la dimensión cultural, del modo como ha sido efectuado en las disciplinas preceden- 
tes. Hemos intentado demostrar la trascendencia de las estructuras de rasgos culturales en el proceso de transformación, esta significación da vigencia a este verdadero reto a los estudiosos de la Teoría Cultural: ser capaces de crear instrumentos medicionales de los principales conceptos de su dominio para la aplicación en los estudios de Modernización.

Creemos que este desafío es uno de los más importantes de esta hora para los cultores de la Antropología, quienes por lo demás siempre han sido reacios a la participación activa en el delineamiento $y$ diseño de los elementos culturales actuales. Sin embargo, la época de transformaciones que vivimos hace imperativo que las disciplinas que se dirigen al conocimiento de los factores que inciden en el comportamiento humano tomen nota de esta situación. El potencial de la Teoría Cultural en los estudios de Modernización necesariamente comienza por este proceso de concreción empírica.

Una segunda característica de los estudios actuales de la Modernización nos demuestra que gran parte de sus esfuerzos han estado dirigidos a describir los elementos que configuran la "sociedad tradicional", el "proceso transicional" y la "sociedad moderna", es decir, la situación inicial, el proceso y la situación terminal de la Modernización. Sin embargo, no se ha prestado gran atención a los efectos culturales de los cambios sectoriales, globales e individuales que la dinámica del proceso ha generado. De este modo, la transformación de la sociedad tradicional ha seguido un esquema de "ensayo y error", que no puede enorgullecer a los planificadores, cuando las consecuencias del cambio han devenido en un aumento de las patologías sociales, conflictos culturales y ruptura de los sistemas normativos, de características tan pronunciadas que llevan a muchos preguntarse por lo deseable de las ventajas que las transformaciones asociadas a la Modernización conllevan.

Este hecho configura, a mi juicio, el segundo gran desafío a la Teoría Cultural: diseñar políticas de transformación que compatibilizen el cambio con la estructura normativa y cultural de los actores sociales, de modo que los efectos secundarios sean controlados de una manera positiva y verdadera para los sujetos de la transformación. $Y$ el reto no es sencillo: se trata nada menos que debe vincularse la Teoría Cultural al proceso de cambios, en forma inseparable y fundamental, para garantizar una modernización de seres humanos, instituciones y sociedades, para el bienestar general y no para una disolución ineluctable de sus estructuras culturales en aras de simples cambios materiales. 


\section{BIBLIOGRAFÍA}

1. Foster, G.: Las Culturas Tradicionales y los Cambios Técnicos. Fondo de Cultura Económica, México, 1964.

2. Germani, G.: Urbanización, Desarrollo y Mo dernización. Ed. Paidós, Bs. As., 1976.

3. Goodenovgh, W. Cultura, Lenguaje y Sociedad en: Kahn, J.: El Concepto de Cultura. Ed. Anagrama, España, 1971.

4. KLuскнонn, C.: El orden moral en una socie- dad en expansión en: Germani, Ch.: Urbanización, Desarrollo y Modernización. Ed. Paidós, Bs. As., 1976, pp. 82-96.

5. Linton, R.: Estudio del Hombre. Fondo de Cultura Económica, México, 1965.

6. Redfield, R.: El papel Cultural de las Ciudades en: Germani, G.: Urbanización, Desa. rrollo y Modernización. Ed. Paidós, Bs. As., 1976, pp. 7-79. 